\title{
Toplam Kalite Yönetiminde Ahilik ve Kaizen Felsefesi
}

\author{
${ }^{1}$ Cem ALPARSLAN, ${ }^{2}$ İbrahim AKSOY and ${ }^{3}$ İhsan TOKTAŞ \\ ${ }^{1}$ Recep Tayyip Erdoğan Üniversitesi, Makine Mühendisliği Bölümü, Rize Türkiye \\ ${ }^{2}$ Ankara Yıldırım Beyazıt Üniversitesi, Makine Mühendisliği Bölümü, Ankara Türkiye \\ ${ }^{3}$ Ankara Yıldırım Beyazıt Üniversitesi, Endüstriyel Tasarım Bölümü, Ankara Türkiye
}

\section{Özet}

Geçmişten günümüze yapılan üretimlerin tamamı her zaman müşteri ihtiyaç ve beklentisi doğrultusunda olmuştur. Müşterilerin bu ihtiyaç ve beklentilerinin üç temel unsur ile karşılanabildiği belirlenmiştir. Bu üç temel unsurun ise kalite, maliyet ve teslimat olduğu anlaşılmıştır. Sıralanan üç unsuru optimum seviyede dengelemeyi başaran şirketler, pazarda daima bir adım önde olmuşlardır. Bu bağlamda standartlaştırma ve sürekli iyileştirme metodolojileri kullanılarak tüm endüstrilerde çeşitli metotlar geliştirilmiş ve şartnameler oluşturulmuştur. $\mathrm{Bu}$ çalışma kapsamında standartlaştırma ve sürekli iyileştirme metodolojilerinin günümüz endüstrisinde kullanım alanları ve amaçları incelenmiştir. Ahilik sistemi başta olmak üzere geçmişten günümüze yapılan çalışmalar araştırılarak kullanılan yöntemlerin avantajları gözlemlenmiştir.

Anahtar Kelimeler: Sürekli İyileştirme, Kaizen, Gemba Kaizen, 5S, Kalite Yönetim Sistemi, Standartlar, Ahilik, Ahi Kuruluşları

\section{Ahi Institute and Kaizen Philosophy in Total Quality Management}

\begin{abstract}
All of the productions from past to present have always been in line with customer requirements and expectations. It has been determined that these needs and expectations of the customers can be met with three basic elements. It has been understood that these three basic elements are quality, cost and delivery. Companies that have managed to balance the three listed elements at the optimum level have always been one step ahead in the market. In this context, various methods have been developed and specifications have been created in all industries by using standardization and continuous improvement methodologies. In this study, the usage areas and purposes of standardization and continuous improvement methodologies in today's industry were examined. The advantages of the methods used were observed by researching the studies carried out from the past to the present, especially the Ahi system.
\end{abstract}

Key words: Continuous improvement, Kaizen, Gemba Kaizen, 5S, Quality Management System, Standards, Ahilik, Ahi Instution

İletişim Yazarı: Cem Alparslan. Adres: Recep Tayyip Erdoğan Üniversitesi Makine Mühendisliği Bölümü, Rize Türkiye. E-posta: cemalparslan1995@gmail.com 


\section{Giriş}

Endüstrinin gelişmesiyle birlikte hammaddelere ve üretime olan ihtiyaç artmıştır. Artan ihtiyaçlar müşteri talep ve şikayetlerinde de paralellik göstermiştir. Bu bağlamda Japonlar tarafından geliştirilen yöntemler birçok şirketlerin gelişmesinde ve pazara liderlik etmesinde etkili olmuştur. $\mathrm{Bu}$ yöntemlerden biri olan kaizen neredeyse dünya devi markaların tamamında kullanılmaya başlanmıştır. Bugün, dünya üzerinde imalatçılardan hastanelere, bankalara, yazılım geliştirenlere ve hükümetlere kadar pek çok organizasyon kaizen felsefesini, zihniyetini benimseyerek fark oluşturmaktadır.

Japonlara göre hayat felsefesi olan "Kaizen' sözcüğü herkesi hem yöneticileri hem işçileri, kapsayan iyileştirme demektir [1]. 'Kai' (sürekli değişim) ve 'Zen'” (iyi, daha iyi) olmak üzere iki farklı kavramı içeren kelime sürekli iyileşme (daha iyiye değişmek) anlamına gelmektedir [2]. Sürekli iyileştirme işlemleri, çalışan her bireyin düşünce ve davranışlarını tartışmaya açması sonucunda ortaya çıkan sorunlara cevap aramasıdır. Ayrıca bu kelime, her geçen dakikanın, saatin, günün bir öncekilerden daha iyi olması için sosyal yaşamda, evde ve işyerinde sürekli olarak çaba göstermek felsefesi ifade eder. 1950 yılında Japonya'da ortaya çıkan iş gücü sıkıntısı sonucunda iş sözleşmeleri ve yeni yönergeler ile meydana gelen kaizen ilk olarak Dünya markası olan Toyota'nın verimliliğini artırmak için 1986 yılında Imai Masaaki tarafından uygulanmıştır [3-5]. Toyota üzerinde yapılan çalışmalarda fabrika verimliliği, müşteri memnuniyeti, ürün kalitesi, problem çözme becerileri, iş güvenliği, çalışan morali, üretim hızı, hızlı teslimat vb. birçok olgunun iyileştiği gözlemlenmiştir [6-8]. Tüm bu uygulamalar sonucunda küreselleşme altında neredeyse endüstrideki tüm alanlarda kaizen uygulamaları farklı çalışmalarla yapılmaya başlanmıştır. Kaizen terimi yıllar boyunca kendisini geliştirmiş ve yönetim teorilerini, felsefeleri hatta araçlarını bir araya getirerek tek bir sistem altında toplamıştır. Temelinde, işçiler tarafından yapılan işlerde sürekli iyileştirmeler yatmaktadır. Kısacası sürekli iyileştirme yapılan proseslere öncelik vermektedir. Çalışanların proseslere yönelik yaptıkları işleri, çabaları destekleyen bir yönetim sistemidir. Bu sisteme göre hiçbir akış, hiçbir operasyon küçük bir iyileştirme yapılamayacak kadar hatasız, mükemmel değildir [9]. Nerede bir iyileştirme olursa, orada kalite ve verimlilikte bir yükselme meydana gelecektir. Çünkü kalite, iyileştirilebilen her şeydir. Tüm bu değişimlerin sonucunda, açılmış bir şemsiye olarak kaizen felsefesini düşünürsek, şemsiyenin altında şu birimleri görmemiz olasıdır [10,11].

Tablo 1. Kaizen Felsefesi 


\begin{tabular}{l|l}
\hline - Müşteri yönelimi ve memnuniyeti & - Küçük grup faaliyetleri \\
- Toplam kalite kontrolü & - Sifir hata \\
- Öneri sistemi & - Isşci ve yönetim işbirliği \\
- Otomasyon & - Verimlilikte iyileştirme \\
- Kalite çemberleri & - Yeni ürünlerin geliştirilmesi \\
- İşyerlerinde saygi ve disiplin & - Tam zamanında üretim \\
- Toplam verimlilik & - Kalite iyileştirmesi \\
\hline
\end{tabular}

Yönetime, üretime ve birçok alana sağladığı avantajlar sonucunda kaizen terimin kendi içerisinde gelişmesi devam etmektedir. Bu nedenle kaizen kelimesi başına "gemba" kelimesini alarak yeni bir yöntem ile endüstrinin gelişmesine katkı sağlamaktadır. Japon işletme teorisinde gemba sözcügü̈, imalatta işin yapıldığı yer anlamına gelmektedir. Geniş bir anlam ile gemba geliştirme, üretim ve satış olmak üzere üç ana faaliyetin oluşum yeridir [11]. Son yıllarda büyük veya küçük tüm işletmelerdeki en temel hedefi çeşitlenen tüketici arzuları sonucunda meydana gelen değişimlere paralel olarak daha fazla ürünü, yüksek kalitede, düşük maliyete imal edip, daha kısa sürelerde müşterilere ulaştırabilmek olmuştur. İşletmeler kalite, maliyet ve teslimat hedeflerine ulaşmadan başarı yakalayamazlar. Bu yüzden, işletmelerde yer alan bütün yönetim fonksiyonları bu üç hedefe hizmet etmelidir [12]. Geçmiş oluşumlar göz önüne alındığında da aynı 3 noktada odaklanıldığ1 öngörülmektedir. Bu oluşumlara örnek olarak Ahi Teşkilatı verilebilir. Ahi teşkilatlarında amaç kalite, müşteri memnuniyeti ve yardımlaşmayı temel alır. Günümüzde bu kavram esnafa özgü bir kavram olarak algılanıyor olsa bile geçmişten günümüze hatta geleceğe 1şık tutan daha derin ve geniş anlamlar ifade etmektedir $[13,14]$.

\subsection{Gemba kaizende kalite, maliyet ve teslimat}

Günümüzde tasarım, üretim, teslimat ve hizmet olanakları, düşük fiyat nedeniyle üretici firmalar arasında rekabet oluşturmaktadır. Sürdürülebilir ve rekabetçi üstünlük sadece maliyet üzerine değil; kalite, maliyet ve teslimat bileşimini ele alır. Bu nedenle, kaizen kavramında bu üç olgu oldukça önemli yere sahiptir.

Kalite, bir sonuçtan daha fazlası olduğu için standartları korumak ve hiçbir hatalı ürünün sonraki müşteriye geçmediğinden emin olmak demektedir. Bunun için çalışanlar arasında öz disiplini inşa etmek kaizen felsefesinin en önemli adımlarından biridir.

Maliyet, gelişmekte olan firmalar için en önemli yapı taşıdır. Kaizen için maliyet yönetimi önemli bir noktadır. Çünkü maliyet yönetimi maliyetleri düşürmeye uğraşırken veya onu hedef düzeyde tutarken iyi kalitede ürün ve hizmet geliştirme, üretim ve satışı denetlemektir. Gemba kaizene göre maliyeti azaltmak için 7 faaliyetin eş zamanlı olarak yürütülmesi gerekmektedir. 

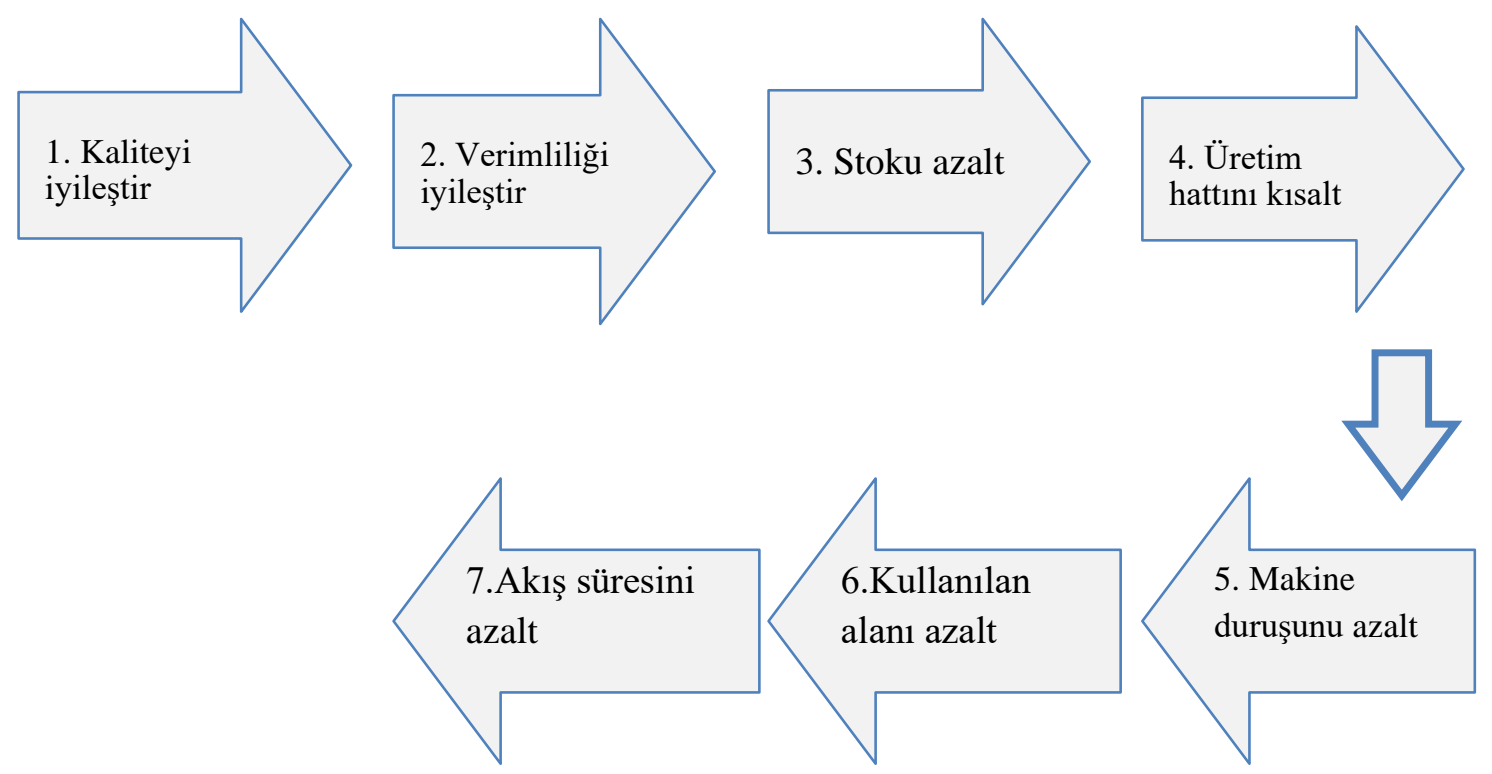

Şekil 1. Kaizende maliyet azaltma uygulaması [11]

Teslimat, ürün veya hizmet hacminin zamanında teslimi demektir. Gemba için önemli kurallardan biri, gereken miktarda ürün veya hizmetin müşteri ihtiyacını karşılamak üzere zamanında eline ulaştırılmasıdır.

\subsection{Ahilik teşkilatında kalite, maliyet ve teslimat}

Ahi kelimesi Arapça anlamı kardeş olan bir kelimedir. Türkçenin ilk sözlüğü olarak bilinin Divánü Lügâti't-Türk içerisinde ahi kelimesi eli açık, cömert anlamında kullanıldığı ve Türkçe olan akı kelimesinden geldiği bahsedilmektedir. Türklerin İslamiyeti topluluk halinde kabul ettiği zamanlarda, Türk örf ve adetleri ile İslam inancını kaynaştırmak amacıyla Ahilik düşünce sistemi ve yaşam tarzının oluşturulduğu bilinmektedir. $\mathrm{Bu}$ düşünce sistemini yaşam tarzı olarak benimseyen kişilere ahi denilmektedir. Ahiler tarafından kurulup geliştirilen kuruluşlara ise ahi birlikleri denilmektedir. Esnafın ticaret hayatını, ekonomik gücünü organize etmek iyileştirmek için ortaya çıkan Ahilik zamanla eğitim, sosyal, askeri ve siyasi alanlarda farklı faaliyetler geliştirerek günümüze kadar etkileri devam eden bir teşkilat olmuştur. Ahilik teşkilatında üretilecek ürünler her meslek grubu ve sanatkarlar için belirli kurallar çerçevesinde üretilirdi. Üretilen malzemeleri ise belirli fiyatlar aralığında satabilirlerdi. Bu sayede toplumsal israftan korunmuş olunurdu. Toplumsal alınan kararlar doğrultusunda alınan kurallara uymayanlar cezalandırılırdı [15]. Ahilik teşkilatlarında asıl amaç ise az maliyetle kaliteli ürünler ortaya çıarıp, müşteri memnuniyetini artırmaktır. Zaman zaman üretim sınırlamaları getirilerek emeğin değerini bulması sağlanırdı. Bu sayede sadece kaliteli üretim değil fiyat ve standardizasyon üzerinde olumlu etkiler sağlanırdı [16].

Bu çalışmada, sürekli iyileştirme metodolojisinin avantajları ve uygulama alanları araştırılmıştır. Endüstride bu yöntemlerin nasıl uygulandığı ve kaç farklı yönteme ayrıldığı incelenmiştir. Kalite 
ve standartlaştırmanın en iyi şekilde uygulanması için dünya genelinde kabul görmüş metotlar, şartnameler ve yönetim sistemleri belirlenmiştir. Ayrıca, sürekli iyileştirme konusunun geçmişte ele alınış yöntemleri ve bu yöntemler üzerinde yapılan çalışmalara, sağladı̆̆ı avantajlara değinilmiştir.

\section{Gemba Kaizen Standartları ve Avantajları}

Günlük işletme faaliyetleri, üzerinde anlaşılmış belli formüllere göre işlev göstermektedir. Bu formüller açık bir şekilde yazıldığında, standartlar haline gelmektedir. Standart bir amacı gerçekleştirmek için kararlaştırılan yoldur. Bir ürünün üretimi, süreçlerin yönetilmesi, hizmetlerin sağlanması veya tedarik sistemlerini içerebilir. Standartlaştırmak istatistik veri elde etmeyi, hataların kök nedenine inerek daha kolay iyileştirme yapmayı sağlar. Gembadaki en önemli şeylerden biri oluşturulan standartları korumak ve sürekli geliştirmektir [7]. Kaizen terminolojisine göre söylersek, Standartlaştır-Yap-Sına-Uygula (SDCA) çevriminin uygulamaya geçilmesidir. $\mathrm{Bu}$ çevrimde mevcut düzensizlikleri SDCA ile standartlaştırdıktan sonra yeni iyileştirmeler için Planla, yap, sına, uygula (PDCA) çevriminin ilk evresi olan planlama yapılır. $\mathrm{Bu}$ sistem verimlilik \%100 olana kadar devam eder.

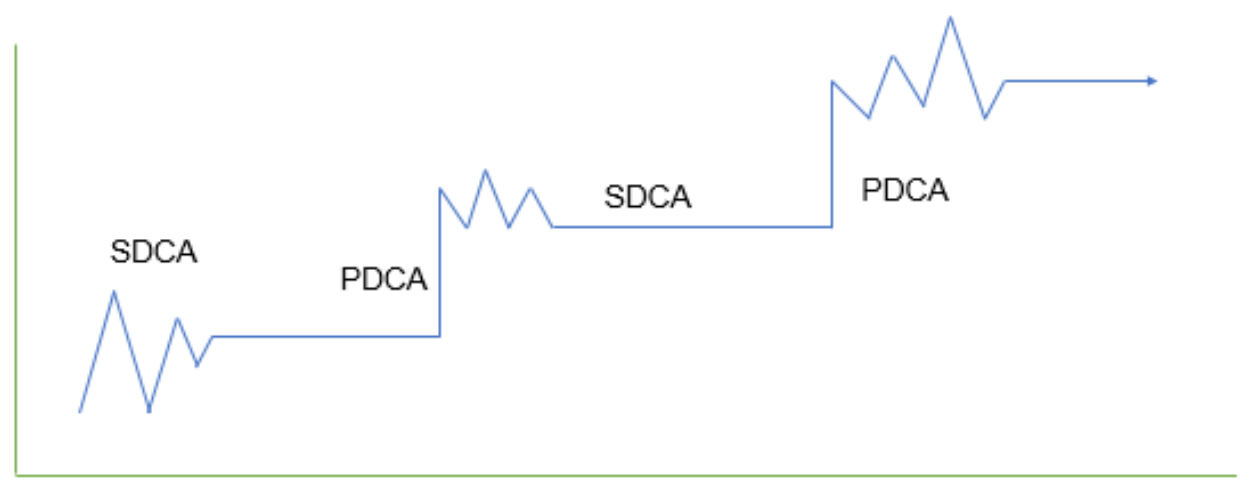

Şekil 2. Kaizende Standartlaştırma (PDCA-SDCA) döngüsü.

Gemba kaizen üzerinde standartlar bir işi yapmak için en kolay, en iyi ve güvenilir yolu temsil etmektedir. Standartlar bilgi birikimi (know-how) ve uzmanlıkta en iyi yolu göstermektedir. Uygulanabilen standartlar sayesinde performans ölçümleri gerçekleştirilerek faaliyetlerdeki sebep-sonuç arasındaki ilişki gözlemlenebilir [17]. Ayrıca standartlaştırılmış iş akışının getirdiği avantajlar oldukça fazla olmaktadır. Bu avantajlardan bazıları şu şekildedir [18];

- Çalışanların öz disiplin kazanmasına yardım eder.

- Hatalı ürün ve stok fazlası gibi anormalliklerin giderilmesini sağlar.

- Gereksiz iş hareketlerini (aşırı yük kaldırma) azaltır.

- Önemli lojistik sorunları kolay yoldan çözmeye yardımcı olur. 
- Kalite sorunlarını görünür kılar.

- İş verimliliğini artırarak maliyeti azaltır.

- İş kazalarının sebeplerinin ortadan kalkmasına ve iş kazalarının azalmasına yardımci olur.

- Hatalı ürün ve stok fazlası gibi anormalliklerin giderilmesini sağlar.

- Çalışanın moralini, motivasyonunu yükseltir.

- Problem çözme yeteneği kazandırır.

\subsection{Kaizende israf}

Değer katmayan her türlü faaliyet kaizen üzerinde israf olarak nitelendirilmektedir. Muda kelimesi Japonca'da israf anlamına gelmektedir. Yapılan çalışmalar doğrultusunda sürekli iyileştirme metodolojisine göre insan hayatında 7 temel israf olduğu belirlenmiştir [19]. Bu 7 temel israfın azaltılması sonucunda Gemba kaizenin verimli olabileceği ön görülmektedir $[11,20]$.

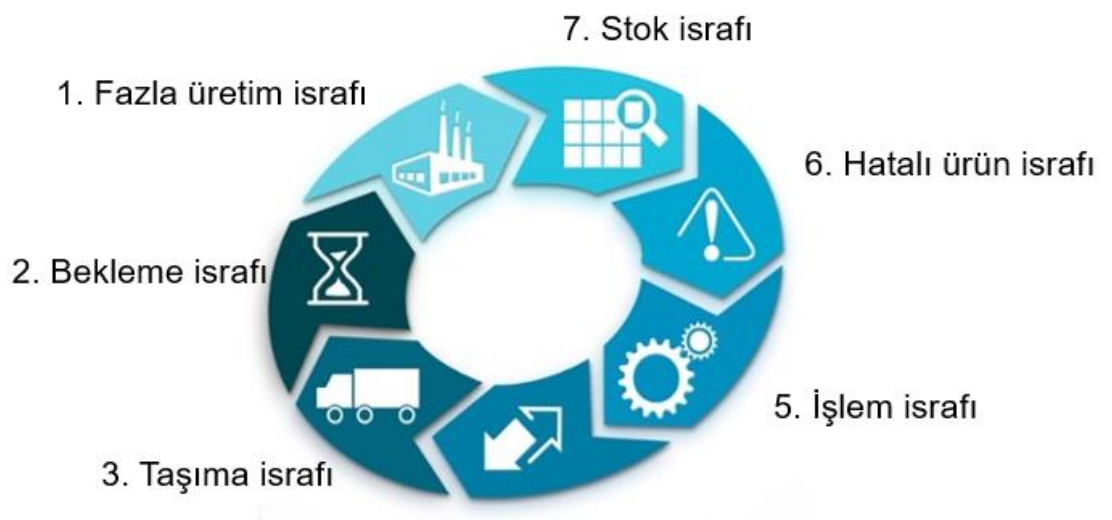

4. Hareket israfı

Şekil 3. Gemba kaizen üzerinde israf türleri

Fazla üretim mudası, tüm mudalar içerisinde en kötüsüdür. İnsanlara yanlış bir güven duygusu verir, tüm sorunları örtmeye yardım eder ve üretim alanında kaizen için ipucu sağlayacak bilgiyi gizler. Fazla üretim mudasının yapılmasındaki en önemli sebep operatörlere gereğinden fazla yetki verilmesi ve üretim hane içerisindeki makinelerin boş kalmasının zarar ettirdiğini düşünmek olduğu yapılan çoğu çalışmada belirlenmiştir. Fazla üretim yapılması sonucunda ise stok mudası meydana gelir. Depoda duran fazla ürünün zamanla kalitesi bozulur. Buda malzemelerin kullanılmamasına ve israf olmasına neden olur. Hatalı ürün mudası ise üretimi kesintiye uğratır ve üretim aşamasında yapılan tüm işlemlerin tekrardan yapılmasına sebep olur. Kaizene göre bir kişinin vücut hareketi doğrudan değer katmıyorsa üretken değildir. Bunun sonucunda hareket mudası meydana gelir. Üretim sektöründe yerleşim (uzun yürüme, taşıma mesafeleri), uzun 
hazırlık süreleri, eğitim eksikliği, yetersiz süreçler, yetersiz bakım, yetersiz çalışma metotları, bağlılık eksikliği, liderlik eksiliği vb. durumlar muda oluşmasının nedenleri olabilmektedir [21].

\section{Toplam Kalite Yöntemi}

Üretilen sağlam ürünlerin oranlarını artırmak amacıyla 1920'li yıllarda kalite kontrol prosesi meydana gelmiştir. Sanayi devrimi ile birlikte tüm ilgi kalitenin kontrolünden ayrılıp, kalitenin güvencesi üzerine toplanmıştır. Çünkü kalite güvencesi, hatalı son ürün oranını en aza indirebilecek operasyonel süreç ve yöntemleri geliştirme çabası doğrultusunda imalat öncesi planlamaya dayanan bir etkinliktir. Kalite ifadesi düşünülürken üç önemli kalite kavramının arasındaki farkların anlaşılması gerekmektedir. Bu kavramlar; kalite kontrol, kalite güvencesi ve toplam kalite yönetimidir.

Kalite kontrol, standartlara uygun olmayan ürünlerin belirlenmesi ve bu ürünlerin ayrıştırılmasını içeren en eski kalite kavramıdır. Üretim aşamaları tamamlandıktan sonra hatalı parçaların ayrılmasına, bu parçaların kurtarılmasına ve iadesine ilişkin tüm süreçlerde kalite kontrol ön plandadır. Oldukça fazla ıskarta, hatalı ürün, hurda ve yeniden işleme gibi durumları güvence altına alabildiğinden yenileşen endüstrilerde çok kullanılan bir yöntem olmaktan uzaklaşmaktadır. Kalite güvencesi, proses esnasında veya öncesinde meydana gelebilecek öncelikli hataların oluşmasını engellemeye çalışan bir süreçtir. Ürünün önceden belirlenen standartlara uygunluğunu garanti altına almak için önemli bir adımdır. Basit olarak ifade edecek olursak, hatasız üretim sağlayabilmek için kullanılan her yöntem veya araçtır. Bu yöntemde amaç oluşacak hatayı sıfira indirebilmektir. Toplam kalite yönetimi (TKY), verilen iki kavramı içerisinde kapsadığı gibi onları daha kapsamlı hale getirerek geliştirir. TKY de amaç müşteriyi her zaman memnun etmektir. Çalışan herkese bu amacın aşılanabilmesi için imkanlar verilerek, kalite kültürünün oluşturulması savunmaktadır. Çünkü bu yöntemde en önemli şey müşteridir. $\mathrm{Bu}$ sistemde bir diğer önemli unsur ise eğitimdir. Eğitimlerin belirli bir amacı vardır. Bu amaçlara uygun hareket edebilmek kritik noktadır. Örneğin, iş kazalarını azaltmak veya ortadan kaldırmak, ürün kalitesini artırmak, çalışanlar arasındaki saygı ve iş birliği kazandırmak, işçilerin verimliliğini artırmak, yeni iş süreçleri geliştirmek, yapılan işlerin standartlar haline getirmek gibi amaçlar sonuçlandırıldığında iyileştirme meydana gelir.

Kaizen kavramında en önemli unsurlardan biri olan kalite aslında toplam kalite yönetiminin geliştirilmesi sonucunda elde edilen bir olgudur. Bu yüzdendir ki eski kuruluşlardan biri olan Ahilik Teşkilatı ile kaizenin asıl amaçları benzerlik göstermektedir. $\mathrm{Bu}$ iki sistem içerisinde kullanılan ve ortak olan konulardan bazılarını motivasyon-moral, müşteri önceliği ve katılımc1 liderliktir gibi sıralamak mümkündür. Kalite felsefesinde işin 'nasıl' değil " neden' yapıldığı esas alınmalıdır. Çalışanlara bu eğitim verilmelidir. Çalışanlar sürekli eğitime ve değişime açık olmalıdır. Çünkü eğitim çalışanların motivasyonunu arttırmakta ve başarma onuru ile işe özendirmede önemli rol oynamaktadır. Bunda insan davranışlarının istenilen doğrultuya yönlendirilebilmesi önem taşımaktadır. Kısacası, iki sistemde de eğitim, müşteri memnuniyeti, 
düşük maliyet, yüksek kalite, standartlaştırma, liderlik, açı fikirlilik ve saygı gibi unsurları birbirine bağlayan tek noktadır.

\section{Ahilik Teşkilatı ve Uygulama Alanları}

Ahilik Teşkilatında şirket/kurum değil sistem referans alınmıştır. Sistemin sürdürülebilmesi için eğitim, kalite ve dürüst rekabete odaklanılmıştır. Bu sistemde üretilen malın kalitesinden esnaflar sorumlu tutulurdu. Ürün kalitesi düşer ise esnaflara ürünler geri verilir, kaliteyi tekrar eski haline getirmediği taktirde meslekten men edilirdi. Böylece tüm esnafların işini en kaliteli bir şekilde yapması sağlanırdı. Ayrıca, sistem içerisindeki eğitim ile kendi misyonlarına uygun kaliteli gelecek nesiller yetiştirilirdi. Hiyerarşik bir yapı düzeni sağlanarak sanatkar veya esnaf olmak isteyen öğrencilere yamak, çırak, kalfa ve usta gibi unvanlar verilerek mesleki açıdan eğitimler verilirdi. $\mathrm{Bu}$ şekilde belirli bir eğitim sisteminden geçirilen kişiler kabiliyetlerine göre medreselerde eğitilirdi. Böylece serbest rekabet veya haksız kazanç yolları kapatılarak, bütün topluma ve ekonomiye fayda sağlanırdı. Tüm bu sistemlerde ekonominin önemli olduğu vurgulanırdı. Çünkü gerçek bağımsızlığın ancak iktisadi bağımsızlıkla kazanılabileceği bilinirdi. Bu birliklerdeki asıl amaç ile sergiledikleri tutum ve davranışlar, bir atın kulaklarına benzetilirdi. Ne birbirinden ayrılır ne de biri ötekinin önüne geçebilirdi. Daima aynı yükseklikte ve aynı yönde hareket ederdi [22].

Günümüzde Ahilik Teşkilatı farklı isim ve kuruluşlar altında halen devam etmektedir. 5373 sayılı Esnaf Dernekleri ve Esnaf Birlikleri Kanunu ile Cumhuriyetin ilk esnaf sanatkar örgütlenmesi oluşturulmuş. Daha sonra 1964 yılında 507 sayılı Esnaf ve Sanatkarlar Kanunu belirlemiş. Devamında ise 2005 yılında ortaya esnaf sanatkarlar teşkilatı olarak bilinen TESK 5362 sayılı Esnaf Sanatkarlar Meslek Kuruluşları Kanunu ile kurulmuştur. Bu birlikler günümüzde modern Ahilik birlikleri olarak adlandırılabilirler.

\section{Kaizen Uygulamaları}

Kaizen felsefesi, şirketlerin verimliliğini artırdı̆̆ı ve minimum çabayla yüksek kalitede ürünler üretmeyi amaçladığı için büyük ilgi görmüştür. Kaizenin uygulanması için sorun ve iyileştirme ihtiyacı olduğunu kabul etmek gerekmektedir. Kaizen yapılacak yerdeki ekip üyelerinin kaizeni benimsemesi özellikle yöneticilerin kabul etmesi önemlidir. Forbes ve Ahmed'e göre kaizenin uygulanmasında çalışanların rolü dört genel seviyeye ayrılmıştır. Üst yönetim, orta yönetim, denetçiler ve çalışanlar. Üst yönetim, hedeflere ulaşmak için temel yeniliklerinden, orta yönetim ve denetçiler ise operasyonel iyileştirmelerden sorumludur. Çalışanlar ise süreç içerisinde kabul edilen ve standartlaştırılan her şeyden sorumludur. Kısacası bu dört farklı grup kaizen çalışması için israfi azaltmak, süreçleri basitleştirmek ve iyileştirmekten sorumludur [23]. Endüstride uygulanan bazı kaizen çalışmaları ise şu şekildedir; 
Chan ve Tay, bir matbaa şirketinde verimliliği artırmak için 2 farklı kaizen uygulaması gerçekleştirmişıler. Fabrikada kullanılan 3 farklı araç üzerinde hat dengeleme, standartlaştırılmış yerleşim ve standartlaştırılmış iş akışı çalışması yapmışlar. Çalışma sonucunda yalın üretim araçlarının imalat sektörü dışında neredeyse tüm insan hayatında kullanılabileceğini gözlemlemişler [24]. Arya ve Choudhary, Hindistan'daki bir mengene imalatı yapan şirket üzerinde kaizen uygulamaları gerçekleştirmişler. Üretim teknikleri, teslim süreleri ve maliyetleri üzerinde çalışmalar gerçekleştirmişler. Yaptıkları çalışma sonucunda envantere erişim süresini $\% 87$, ürün için kat edilen toplam mesafeyi $543.75 \mathrm{~m}$ ve imalat için toplam süreyi $\% 46.08$ azaldığını belirlemişler. Ayrıca, işçilerde işyerini temiz tutma alışkanlığı kazandığını gözlemlemişler [25]. Koopmans ve Bechman yaptıkları çalışmalar sonucunda farklı iş istasyonları arasında malzeme taşıma maliyetlerini en aza indirmek için yerleşim problemlerinin Kaizen yöntemleri ile çözülebileceğini, etkili tesis yerleşimi ile malzeme taşıma maliyetlerini en aza indirebileceklerini ve devam eden iş süreçlerinin azaltılabileceğini belirtmişler [26]. Prashar, direksiyon imalat şirketinde düşen müşteri talebi ve artan hammadde üzerine kaizen çalışmaları gerçekleştirmiş. Kuruluş içerisinde kaizen araçlarını kullanarak sorunların temel nedenini bulmuş. Yalın süreç tekniklerini kullanarak montaj hattını geliştirerek vaka organizasyonu, envanterini \%66 oranında, kusur oranını \%32 oranında azaltmış. Ayrıca, etkin bir şekilde yönetilen ekipman ile insan gücü ve depolama alanı sağlandığı belirlemiş [27]. Vento vd. çalışmalarında, Meksikalı bir şirkette planlama aşamasında kaizen uygulamasından elde edilen faydalar üzerinde hem yönetimsel bağlılığın hem de insan kaynaklarının mesleki gelişimlerini analiz etmişler. $\mathrm{Bu}$ araştırma sonucunda, iyileştirme ve değişime katkıda bulunduğunu, organizasyon içinde israf ve iyileştirme desteğinin arttı̆̆ını belirlemişler. Son olarak bu araştırma, entegre insan, malzeme, bilgi, ekipman ve enerji sistemlerinin iyileştirilmesine odaklandığından, endüstri mühendisliği ve mühendislik ve operasyon yönetiminin yönetim disiplinlerine katk1 sağladığını anlamışlar [21]. Arya ve Jain, Hindistan'daki küçük ölçekli Endüstrilerde kaizenin faydalarını incelemişler. Kaizenin uygulanmasının, işlem süresini kısalttı̆̆ını ve çalışma alanı yönetimini iyileştirdiğini gözlemlemişler [28].

\section{Tartışma}

Öncelikle, bu çalışma yapılırken üretim sektöründeki verimliliğin nasıl artırabileceği sorusuna cevap aranarak başlandı. Bu soruya verilebilecek en iyi cevabın Japon felsefesi olan kaizen olduğu ön görülüp kaizen üzerine araştırmalar gerçekleştirildi. Genel olarak kaizenin iki ana bileşen olduğunu, bunların daha iyi ve sürekli faaliyetler için iyileştirme/değişim olduğunu gözlemlendi. Bu bileşenlerden biri olmadan orada kaizen olduğunu söylenemeyeceği anlaşıldi. Buna örnek verecek olursak, bir iş adamı yaptığın işin riskini önlemek için herhangi bir değişiklik yapmadan her zamanki gibi işine devam ediyor ise süreklilik bileşenini içeriyor demektir. Buna karşılık, iş adamı belirli bir zamanda daha iyi sonuçlar elde etmek için işini genişletiyorsa; süreklilik olmadan sadece iyileştirme bileşenlerini içeriyor demektir. Bu nedenle, bu bileşenler hiçbir şekilde ayrılamaz. Yani bir iş adamı süreklilik sağlamadan işlerini genişletemez. 
İkinci olarak, Kaizen için önemli 3 unsur olduğunu bunların kalite, maliyet ve teslimat olduklarını gözlemlendi. $\mathrm{Bu} 3$ ana unsur birbirinden ayrı düşünülemeyeceği anlaşıldı. Günümüzde tüm üreticiler ürettikleri malı olabildikçe az maliyetle üretmek istiyor. Fakat bir mal ucuza üretildiği kadar kalitelide üretilmelidir. Ayrıca bu üretimin sonucunda müşteriye en hızlı şekilde ulaşmalıdır ki üretilen mal yüksek verimlilikle satılabilsin. Kaizen işte bu 3 ana unsur üzerinde düşünmemizi istiyor. Kaizen sayesinde başarıya ulaşmış kişiler kaizenin kalitenin bir sistem olduğunu veya müşteri gereksinimlerini karşılayan hizmetler için malları ekonomik olarak üretmenin bir aracı olduğunu söylüyor.

Son olarak bir işletmede kaizenin en iyi şekilde uygulanabilmesi ve sonuç alınabilmesi için 2 temel kavramın çok dikkatli bir şekilde gerçekleştiriliyor olması gerektiği anlaşılmıştır. Bunlar $5 \mathrm{~S}$ ve Muda. 5S, bir fabrikanın her tarafında temizlik tertip ve düzenin sağlanmasıdır. Yapılacak çalışmaların temelini teşkil edecek olan 5S önce fabrikaya uygulanmalıdır. Sonra kalıcılığ 1 temin edilerek şirket kültürünün bir parçası haline getirilmelidir. 5S'i kısaca şu şekilde açıklayabiliriz; Seiri-Ayıklama, Seiton- Düzenleme, Seiso-Temizleme, Seiketsu- Süreklilik, Shitsuke- Disiplin. Muda ise Japonca bir kelime olup atık anlamına gelmektedir. Kaizen için ne kadar az muda o kadar çok verimlilik anlamına gelmektedir. Bir üretici üretmek istediği malı sıfır hata ile üretmeyi hedeflemektedir. Bunun için önlemler alması gerekmektedir. Kaizenin ele aldığı muda kavramı üreticinin sıfır hataya nasıl ulaşabileceğini anlatmaktadır. Ayrıca, tüm bu sistemlere benzerlik sağlayan Ahilik oluşumunda izlerinin modernleşmiş toplumda evrimleşerek devam ettiği gerçeğinin kabul edilmesi gerekmektedir.

\section{Sonuç}

Kaizen iş sürecinde sürekli iyileştirmeler yapmak demektir. Kaizen ilkeleri çok esnektir. $\mathrm{Bu}$ nedenle kaizen yani sürekli iyileştirme kavramı farklı disiplinlere uygulanabilir. Yönetim, hizmetler, pazarlama, hesaplar, imalat, insan kaynakları ve mühendislik gibi çeşitli bölümlerde kolaylıkla uygulanabilir. Kaizenin tüm aşamaları özenle uygulanırsa, şirketin en az maliyetle en fazla karı elde etmek için sınırlı kaynaklarını maksimum verimlilikte kullanmasına yardımcı olur. $\mathrm{Bu}$ sayede daha az atık ortaya çıkmış olur. Kaizen uygulamak isteniyorsa çalışanların Kaizen felsefesini benimsemesi gerekir. Kaizen, çalışanlar için uygun şekilde benimsenmedikçe, kaliteli bir şekilde uygulanamaz. Çalışanlara Kaizen ve ilkeleri hakkında eğitim verildikten sonra, yeteneklerinden en iyi şekilde yararlanılabilir ve karşıllı̆ında şirkete fayda sağlanabilir. Kaizenin esnek doğası gereği, niteliği ve büyüklüğü ne olursa olsun her türlü organizasyonda kolayca uygulanabilir. Toyota kadar büyük bir kuruluşta Kaizeni uygulayabilir, market gibi küçük bir işletmede de kaizen uygulayabilir. Kaizenin sonuçları her zaman faydalıdır, her zaman şirketin karını artırmak için en iyi yolda olup olmadığından emin olur. Kaizenin sonuçlarından hiçbir zaman şüphe edilmemesi gerekir, çünkü kaizen uygulamalarının başarı oranı son derece yüksektir. Tüm dünyada kaizen prensiplerini kullanan ve önemli ölçüde kar sağlayan şirketler 
olmuştur. Bu firmaların bazılarının ismi, Toyota, Honda, Fidelty yatırımları, Canon. Bütün bu şirketlerin sahipleri yakaladıkları başarının sırrının Kaizen presiplerini uygulamak ve inançlarını kaybetmemek olduğunu itiraf ediyorlar. Kaizene inanmak çok önemlidir, çünkü bazen kuruluşunuzun tüm yapısını değiştirmeniz gerekebilir ancak bunun sizin iyiliğinizden dolayı olduğunun fakında olmalısınız. Şirketler özellikle uluslararası pazara ulaşmak istiyorlarsa kaizenin önemini anlamalıdır. Çeşitli kural ve düzenlemeleri uygulamakta tereddüt etmemelidir. Başlangıçta, sonuçlar çok açık olmayabilir. Ayrıca, şirketler kaizen nedeniyle tüm operasyonel yapılarını değiştirme fikri ile rahatsız olabilirler. Fakat Kaizen fikrini benimseyip uyguladıklarından birkaç ay sonra gereksiz üretim sıkıntılarının ortadan kalkmaya başladığını ve harcamalarının azaldığını gördüklerinde Kaizeni ve prensiplerini takdir edeceklerdir.

\section{References}

[1] Malik SA, Ye Zhuang T. Execution of continuous improvement practices in spanish and pakistani industry: a comparative analysis. IEEE International Conference on Management of Innovation and Technology Singapore. 2006;2:761-765. doi:10.1109/ICMIT.2006.262323

[2] Palmer VS. Inventory Management Kaizen. Proceedings of 2nd International Workshop on Engineering Management for Applied Technology Austin, USA. 2001; 55-56. doi: 10.1109/EMAT.2001.991311

[3] Imai M. Kaizen: the key to japan's competitive success, McGraw Hill, New York, USA; 1986.

[4] Ashmore C. Kaizen and the art of motorcycle manufacture. Manufacturing Engineer, 2001;80(5):220-222.

[5] Brunet P. Kaizen in Japan. IEE Seminar, Kaizen: From Understanding to Action (Ref. No. 2000/035), London, UK. 2000;1:1-10. doi: 10.1049/ic:20000198

[6] Stewart J. The Toyota Kaizen continuum. 1. ed. Productivity Press; 2011.

[7] Gao S, Low SP. Understanding the application of Kaizen methods in construction firms in China. Journal of Technology Management in China 2013;8(1):18-33.

[8] Al Smadi S. Kaizen strategy and the drive for competitiveness: challenges and opportunities. Competitiveness Review: An International Business Journal Incorporating Journal of Global Competitiveness, 2009;19(3): 203-211.

[9] Aoki K. Transferring Japanese Kaizen activities to overseas plants in China. International Journal of Operations \& Production Management, 2008;28(6): 518-539.

[10] Davis JW. Progressive Kaizen; the key to gaining a global competitive advantage. 1. ed. Productivity Press; 2016.

[11] Imai M. A commonsense approach to a continuous improvement strategy ; Gemba Kaizen. 2. ed. McGraw Hill Press; 2012.

[12] Mika GL. Kaizen event implementation manual. 5. ed. Society of Manufacturing Engineers; 2006. 
[13] Iş̧1k S. Ahilik teşkilatı. 1. bas. Ekin yayınevi; 2017.

[14] Örs H, Şahin A, Bayraktar F, Yücekaya H, Bayraktar L, Kurtoğlu O et al. Postmodern çağda ahilik. 1. bas. Nobel Akademik Yayıncılık; 2016.

[15] Şeker M. Türk islam medeniyetinde ahilik ve fütüvvet-namelerin yeri. 1. bas. Yayıncı Ötüken Neşriyat; 2015.

[16] Uçma İ. Bir sosyal siyaset kurumu olarak ahilik. 2. bas. İşaret Yayınları; 2017.

[17] Whitmore T. Standardized work. Manufacturing Engineering 2008;140(5):171-179.

[18] García-Alcaraz JL, Oropesa-Vento M, Maldonado-Macías AA. Descriptive analysis of kaizen benefits. In Kaizen Planning, Implementing and Controlling, Springer, Cham. 2017;119145.

[19] Ohno T. Toyota production system: beyond large-scale production. $1^{\text {st }}$ ed. Productivity Press, Toyko; 1988.

[20] Prabhuswamy MS, Ravikumar KP, Nagesh P. Implementation of kaizen techniques in TPM. IUP Journal of Mechanical Engineering 2013;6(3).

[21] Vento M, Maldonado Macias A, Alcaraz J. Kaizen planning, implementing and controlling. $1^{\text {st }}$ ed. Springer International Publishing; 2017.

[22] Ekinci Y. Ahilik.13. bas. Mihrabat Yayınevi; 2016.

[23] Forbes L, Ahmed S. Modern construction: lean project delivery and integrated practices. CRC Press, Boca Raton, FL; 2010.

[24] Chan CO, Tay HL. Combining lean tools application in kaizen: a field study on the printing industry. International Journal of Productivity and Performance Management; 2018;67(1):45-65.

[25] Arya AK, Choudhary S. Assessing the application of Kaizen principles in Indian small-scale industry. International Journal of Lean Six Sigma 2015;6(4):369-396.

[26] Koopmans T, Beckmann M. Assignment problems and the location of economic activities. Econometrica 1957;25(1):53-76.

[27] Prashar A. Redesigning an assembly line through Lean-Kaizen: an Indian case. The TQM Journal 2014;26(5):475-498.

[28] Arya AK, Jain SK. Impacts of Kaizen in small-scale industry of India: a case study. International Journal of Lean Six Sigma 2014;5(1):22-44. 